Etnográfica

Revista do Centro em Rede de Investigação em

Antropologia

vol. 12 (1) | 2008

Vol. $12(1)$

\title{
Pessoa e individuação: o poder dos nomes entre os Tupinambá de Olivença (sul da Bahia, Brasil)
}

Person and individuation: the power of names among the Tupinamba of Olivença (south of Bahia, Brazil)

\section{Susana de Matos Viegas}

\section{(2) OpenEdition}

Journals

Edição electrónica

URL: https://journals.openedition.org/etnografica/1618

DOI: 10.4000/etnografica.1618

ISSN: 2182-2891

\section{Editora}

Centro em Rede de Investigação em Antropologia

\section{Edição impressa}

Data de publição: 1 maio 2008

Paginação: 71-94

ISSN: 0873-6561

\section{Refêrencia eletrónica}

Susana de Matos Viegas, «Pessoa e individuação: o poder dos nomes entre os Tupinambá de Olivença (sul da Bahia, Brasil)», Etnográfica [Online], vol. 12 (1) | 2008, posto online no dia 19 junho 2012, consultado o 10 fevereiro 2022. URL: http://journals.openedition.org/etnografica/1618 ; DOI: https://doi.org/10.4000/etnografica.1618

\section{(c) (i) (8)}

Etnográfica is licensed under a Creative Commons Attribution-NonCommercial 4.0 International License. 


\title{
Pessoa e individuação: o poder dos nomes entre os Tupinambá de Olivença (sul da Bahia, Brasil) ${ }^{1}$
}

\section{Susana de Matos Viegas}

\begin{abstract}
Neste texto desenvolvo um debate sobre a pessoa, nomes e individuação, enveredando por uma reflexão sobre mudanças sociais e onomásticas a partir da análise dos nomes registados pelos Tupinambá de Olivença (Bahia) entre o final do século XIX - quando se fizeram os primeiros registos civis no Brasil - e a actualidade.

Tendo em conta a relevância dos "nomes seriados" no Brasil e o seu uso pelos Tupinambá de Olivença, mostro como se apropriaram destes nomes acentuando modos de inserção familiar face ao Estado, ao mesmo tempo que sublinham a originalidade dos nomes no meio social da roça, tornando claro o seu poder nas negociações com o Estado.
\end{abstract}

PALAVRAS-CHAVE: pessoa, nomes, Tupi, cidadania, parentesco, história ameríndia.

SOMOS MUITAS VEZES TENTADOS A PRESUMIR QUE OS NOMES DO registo de nascimento são principalmente dispositivos de subjugação e vigilância dos indivíduos por aparelhos políticos e administrativos estranhos à identidade da pessoa e à experiência vivida. Num dos textos clássicos sobre nomes na antropologia, Martine Segalen diz-nos, por exemplo, que a identificação dos habitantes da comunidade da Bretanha nos "documentos oficiais

l Este texto não teria sido possível sem o debate que tenho desenvolvido nos últimos anos com João de Pina Cabral sobre o tema dos nomes. A pesquisa de campo foi financiada, entre 1997 e 2000 , e entre 2004 e 2005, respectivamente, pelos projectos Ref. PCSH/C/ANT/42/96 e Ref. POCTI/ANT/61 198/2004, da Fundação para a Ciência e a Tecnologia (Portugal). No período entre 2003 e 2005 tive apoio da Fundação Nacional do Índio (Funai), no âmbito do Programa de Proteção e Divulgação do Patrimônio Cultural das Comunidades Indígenas (UNESCO), Edital 2003/02, referência 914/BRA/301, no âmbito da Identificação da Terra Indígena Tupinambá de Olivença (Portaria Funai n. ${ }^{\circ}$ 102/PRES/04, DOU, Seção 2, n. ${ }^{\circ}$ 18, 13/01/2004). 
e administrativos" é "inadequada" para identificar os membros desta comunidade (Segalen 1980: 63). Segalen chama atenção para o facto de existir um fosso entre "a identidade dos indivíduos" tal como figura nos documentos e os nomes de uso quotidiano, desde logo porque os primeiros são em francês e os segundos em bretão, mas também porque esses nomes do registo não se usam na vida quotidiana (Segalen 1980: 63). Como nos lembram Bodenhorn e Vom Bruck, de facto, os registos de identificação são veículos através dos quais "os governos e as instituições por todo o mundo tendem a supervisionar as actividades dos indivíduos" (Bodenhorn e Vom Bruck 2006: 2). Ao mesmo tempo, porém, e como estas mesmas autoras acabam por reconhecer, os nomes do registo de nascimento podem também ganhar um poder reverso, quando por exemplo se tornam veículos de acesso a direitos sociais - como seja no acesso à aposentadoria (reforma) ou na reivindicação de direitos à diferença étnica - como acontece actualmente entre os Tupinambá de Olivença que habitam na região da Mata Atlântica da costa sul da Bahia, sobre quem tenho trabalhado desde 1997 (cf. Viegas 2007).

Os Tupinambá de Olivença fazem parte historicamente da grande família Tupi, que ocupava uma vasta área da costa atlântica há pelos menos três séculos quando os portugueses chegaram ao extremo sul da Bahia em 1500. No território da Mata Atlântica foram vivendo relações com os colonos portugueses nos séculos XVI e XVII, com os missionários jesuítas que ali estabeleceram uma aldeia de índios entre 1680 e 1758 , e depois com o projecto civilizatório iluminista (cf. Almeida 1997; Viegas 2007: 27-37). Entre os projectos de civilidade de costumes, hábitos de fé, de organização do espaço doméstico e de formas de constituição da família, também os nomes pessoais dos índios "aldeados" no período colonial passam a seguir o sistema onomástico português. Nos finais do século XVIII os documentos oficiais referem os índios da Vila de Índios de Olivença por nomes portugueses, tais como João Francisco, Sebastiana, Ana, Manuel, João ou Eugénia (cf. Mott 1988: 110), sendo muito provável que esse sistema onomástico já tivesse sido introduzido em período anterior.

Desde a abertura democrática no Brasil e a partir de finais da década de 1980, quando o Brasil começa a adoptar filosofias indigenistas respeitadoras da diferença cultural, os Tupinambá de Olivença têm-se vindo a dar conta da maneira como os registos de nascimento com data e nome completo são fundamentais no acesso a direitos sociais. $\mathrm{O}$ facto reflecte-se desde logo na expressão "o nome certo" ou "o nome natural" utilizado actualmente pelos Tupinambá de Olivença para se referirem ao nome do registo de nascimento.

Neste texto apresento uma análise do repertório de nomes que encontramos nos registos de nascimento dos índios que habitavam na vila e na mata da região de Olivença há um século atrás (entre 1889 e 1910) até à actualidade. Essa análise conduz-nos a reflectir sobre o contraste entre os nomes utilizados pelos Tupinambá de Olivença entre os finais do século XIX até à década de 
1950-1960 e os actuais. Nesse período anterior verificamos a existência de um repertório marcadamente português, de nomes tradicionais e preexistentes (Pina Cabral 2002: 128), que contrasta com a situação actual de um repertório marcado pela aquisição, inovação e efemeridade, praticado actualmente pelos Tupinambá de Olivença, ao criarem nomes singulares que se pretende que sejam irrepetíveis. Nesta dimensão historicista da análise acentuo uma problematização não linear das transformações entre sistemas lusófonos na sua relação com as noções de pessoa e de individuação. No que diz respeito às transformações ocorridas nas últimas décadas, mostrarei que, se o acesso a um certo tipo de sociedade de consumo (pelos meios de comunicação social, mas também pela circulação regular de mulheres para a cidade) é uma das linhas explicativas da adopção de certos tipos de nomes, há também um outro vector de mudança marcado pela historicidade ameríndia própria do território e pela presença do Estado e da sociedade civil que acompanham esta mudança dos nomes registados. Tal ocorre exactamente no período em que esse registo ganha um valor social importante como forma de acesso a direitos sociais, nomeadamente aos direitos à aposentadoria e aos direitos indígenas.

O texto propõe, em suma, uma reflexão sobre os nomes, a pessoa e os processos de intermediação dos direitos sociais, contribuindo para o vasto debate sobre nomes e pessoa na antropologia, através do qual se conduz a historicidade das práticas onomásticas para a compreensão de questões como o tempo da socialidade e a diversidade de formas de individuação.

NOME E PESSOA

Parece que os nomes Xavante são apenas em parte ou não são de todo para identificar indivíduos particulares (...) (Maybury-Lewis 1975 [1967]: 234).

Quando o nome que se tem é indicativo da pessoa que se é - o nome faz parte do que é a pessoa -, partilhar um nome pode ser particularmente problemático e a individuação um objectivo central do sistema onomástico (cf. Bodenhorn e Vom Bruck 2006: 22). Na citação em epígrafe, Maybury-Lewis diz-nos que, para os Xavante, os nomes não individuam: a mudança de nome que ocorre quando se sobe de estatuto entre os Xavante seria apenas, na sua acepção, um sinal denotativo dessa mudança, na qual "o nome em si" não tem nenhuma relevância (cf. Maybury-Lewis 1975: 234-235). Segundo o etnógrafo, o facto de as mulheres Xavante afirmarem desconhecer o seu nome pessoal seria igualmente explicado por o nome não ser um marcador individual significativo entre os Xavante (Maybury-Lewis 1975: 235). Seguindo uma abordagem ao estudo dos nomes Xavante menos estruturalista, Aracy Lopes da Silva oferece-nos, contudo, uma perspectiva diferente sobre o significado dos nomes entre 
os Xavante e o seu peso ontológico. A autora afirma que o facto de as crianças Xavante não terem nome até muito tarde não implica que os nomes sejam insignificantes, mas sim que "o nome é uma carga demasiado pesada para o seu corpo frágil.” (Silva 1986: 67)

$\mathrm{Na}$ antropologia, o estudo dos nomes é concebido como parte integrante de qualquer abordagem ao conceito de pessoa desde o ensaio clássico de Marcel Mauss (1985 [1938]) e do ensaio de Geertz (1993 [1973]). Ainda que de modo singular, Mauss leva-nos a pensar na importância do estatuto ontológico do nome das pessoas, pois considerava existir uma correlação entre os sistemas onomásticos mais classificatórios e os mais individualizadores; quer dizer, os dois pólos opostos da noção de pessoa que percorrem o seu ensaio. Por um lado, "a personagem", que tipificaria a noção de pessoa nas sociedades primitivas e, por outro, a individuação do self, que marcaria a noção de pessoa moderna e ocidental. Mais recentemente, o tema de pessoa tem sido equacionado de modo radicalmente diferente pela antropologia, desmultiplicando as formas de se pensar na individuação (dos nomes e das pessoas) de um modo bem mais plural, que interessa às actuais estratégias de análise antropológica. Assim, por exemplo, na sua análise dos nomes na Mongólia, Caroline Humphrey (2006) identifica o poderoso estatuto ontológico do nome na individuação da pessoa, considerando que na Mongólia "o nome é a pessoa" e que o nome de um indivíduo marca o seu destino (cf. Humphrey 2006: 159). Assim se explica que haja um esforço pela originalidade absoluta dos nomes: os nomes entre pessoas diferentes que pertençam ao mesmo meio social não podem ser semelhantes (cf. Humphrey 2006: 159-160). Mas, ao mesmo tempo, o nome individua a partir de uma condição fundada na relação, já que, de acordo com Humphrey, "a pessoa deve ser o nome que lhe é dado por outrem" (Humphrey 2006: 160). A individuação, neste sentido, passa por uma relação prévia que é lembrada: a do nominador com o nomeado.

A etnografia de Simon Harrison (1990) sobre nomes entre os Manambu (na região do rio Sepik) na Melanésia enfatiza igualmente a escolha de um nome original, individuante. Harrison sublinha que há um enorme cuidado em escolher-se um nome para a criança que não esteja já "em uso": "todas as pessoas têm que ser completamente inidividualizadas pelos seus nomes e não podem existir homónimos contemporâneos" (Harrison 1990: 61). Um outro sistema onomástico que mais tem sido estudado por relação com a individuação antroponímica é o sistema chinês, onde se presume uma correlação entre o nome pessoal e os destinos pessoais (e.g. Watson 1986; Pina Cabral 2002). A possibilidade de partilhar um nome próprio com alguém que se conheça é tão insuportável que pode levar a mudar-se de local de residência ou a mudar de nome - o que, diferentemente do caso dos nomes em contextos lusófonos (Pina Cabral neste volume; Schritzmeyer 2007), não é visto como um problema (cf. Watson 1986: 622). Rubie Watson, na sua abordagem sobre os nomes na 
China, partindo de uma etnografia das chamadas "aldeias de linhagem" (nas quais, por inerência, todos têm o mesmo sobrenome - Tang, por exemplo), sublinha a importância dos nomes próprios na sociedade chinesa como formas de "individualização" pessoal (Watson 1986: 619). Os homens vão ganhando nomes ao longo da sua vida e, com isso, vão acumulando diferenciações pessoais, enquanto que as mulheres absorvem o nome do marido quando casam, ao mesmo tempo que passam a ser chamadas por tecnónimos de parentesco ("mãe de...") quando têm filhos (Watson 1986: 619) - perdendo, assim, a sua individuação.

No debate americanista, a relação entre nomes, pessoa e individuação tem o expoente máximo no sistema onomástico dos Tupinambá do século XVI e XVII. Numa abordagem comparativa detalhada dos sistemas onomásticos ameríndios e suas diferenças, Viveiros de Castro (1986: 384-390) fez uma sugestão interpretativa para o universo americanista que, desde então, tem vindo a ser considerada como ponto de partida para o debate comparativo. Aí o autor salienta a diferença entre sistemas exonímeos e endonímeos, por um lado, e os mais classificatórios e os mais individuadores (normalmente associados aos exonímeos), por outro. Neste último caso, adquirem-se nomes fora do universo social de pertença e vêem-se os nomes como um atributo não transferível:

De um modo geral, pode-se dizer que a onomástica Tupi-Guarani típica recorre, como fonte ou critério, ao extra-social: natureza, inimigos, deuses. E que os nomes têm uma função essencialmente individualizadora. A ênfase dos sistemas de nominação "canibais" parece ser menos na classificação que na individualização; menos na conservação de um repertório de nomes, ao modo Jê (...), que na aquisição de nomes novos; menos na transmissão visada por esta conservação que na re-nomeação pessoal e instransferível; (...) menos na continuidade com o passado que na abertura para o futuro; menos, enfim, na articulação onomástica de identidades complementares internas ao grupo que na captura de distintividades suplementares no exterior. (Viveiros de Castro 1986: 388$)^{2}$

Os sistemas onomásticos ameríndios endonímeos acentuam a conservação dos nomes como uma espécie de património a ser transmitido entre gerações. Estes sistemas valorizam tanto a transmissão "interna" de nomes que, mesmo quando se adquire o nome fora do universo social, o objectivo é integrá-lo na transmissão intergeracional "dentro do grupo" (cf. Viveiros de Castro 2006 em Hugh-Jones 2006: 89). O caso Tupi-Guarani surge assim no pólo oposto, tendencialmente exonímeo e individuante, buscando nomes singulares que 
garantam a individuação e a descontinuidade temporal sem qualquer propósito sistemático de transmissão de nomes entre gerações.

Os sistemas onomásticos Tukano (Barasana) descritos pelos Hugh-Jones (2006; 1988 [1977]) aproximam-se mais dos endonímeos exactamente por enfatizarem a transmissão dos nomes a partir de um stock de nomes limitado e em perpétua circulação (cf. Hugh-Jones 2006: 74). Christine Hugh-Jones mostra que, para os Barasana, os nomes são a única substância da pessoa que poderá assegurar a sua continuidade para além da morte, porque a substância da alma se herda no nome, enquanto que o corpo físico putrifica (cf. Hugh-Jones 1988: 113, 134). Por isso lhe diziam os Barasana, "se nós não ficássemos com os nomes, morreríamos como um cadáver putrificado" (Hugh-Jones 1988: 165). Os nomes são para os Barasana um repertório fixo e fechado que é transmitido pela linha patrilinear e são considerados património exclusivo de um sib (Hugh-Jones 1988:133). A fixidez deste repertório é assegurada por uma transmissão em ciclos de gerações alternadas (de avô para filho do filho) que, ao mesmo tempo, diz-nos Hugh-Jones, corta a memória genealógica de longo termo: "a memória genealógica é destruída através da repetição dos nomes de geração para geração” (Hugh-Jones 1988: 39-40, 164). Nome e pessoa de tal forma se aliam que, em cada geração alternada, os Barasana têm os mesmos nomes $e$ as mesmas almas (Hugh-Jones 1988: 165). A semelhança de nomes é aqui também, porém, um processo de diferenciação e identificação com os sibs. O poder de diferenciação dos nomes está ligado desde logo, para os Barasana, com o processo de criação do mundo, já que as próprias anacondas (que, ao viajarem no rio e dançarem nas suas margens, criaram os Barasana e os sibs) se individuam por terem nomes diferentes (cf. Hugh-Jones 1988: 33).

Esta breve reflexão comparativa tem por objectivo situar-nos num espectro de relações entre nomes, pessoa e temporalidade que, num extremo, tem o repertório de nomes como um stock fixo e limitado que garante semelhança e continuidade histórica e, no extremo oposto, usa os nomes como um eixo de expansão, individuação e diferenciação que garante a mudança e a descontinuidade histórica. Entre os Tupi Parakanã, diz-nos Carlos Fausto, os nomes não marcam continuidades, não estabelecendo nenhum tipo de relação entre linhas de sucessão geracional "e sim individualização" (Fausto 2001: 399). A reflexão sobre o uso dos nomes pode, portanto, contribuir para uma maior abertura de estratégias comparativas múltiplas no estudo da pessoa e também na relação entre pessoa e parentesco. O estudo dos nomes evidencia, por exemplo, a multiplicidade de formas de individuação e a maneira como estas se combinam com diferentes referenciais éticos e com diferentes temporalidades (cf. Pina Cabral e Viegas 2007).

O assunto não está completamente resolvido nos estudos contemporâneos sobre o parentesco, onde se continua a encontrar na diferenciação entre sociedades de linhagem e sociedades da relação, por exemplo, formas de o equacionar. 
Nesse sentido, Janet Carsten afirma: "O lugar óbvio para procurar as noções de pessoa que enfatizam a conexão ou o não-individualismo pode ser no tipo de sociedades de linhagem, organizadas pela descendência de um antepassado comum." (2004: 88) As estratégias comparativas múltiplas que têm vindo a desenvolver-se na antropologia (cf. Viegas 2007: 68-70) permitem-nos avançar para formas mais sofisticadas e plurais de pensar esta questão da relação entre individuação, relação e temporalidade. Neste campo de reflexão, o estudo dos nomes pode constituir um importante veículo de pensamento antropológico sobre a pessoa, expandindo uma reflexão sobre formas diversas de conceber a individualidade.

\section{NOMES DE USO ENTRE OS TUPINAMBÁ DE OLIVENÇA}

O nome de identificação pessoal que os Tupinambá de Olivença usam na vida quotidiana tanto pode ser o nome do registo de nascimento como todos os outros nomes que os Tupinambá integram numa mesma categoria à qual chamam "apelidos". ${ }^{3}$ Estes apelidos são geralmente os nomes pelos quais as pessoas são referidas e conhecidas numa vasta rede de sociabilidade, ainda que alguns também possam ser, como noutros contextos bahianos, mais restringidos à intimidade ou familiaridade (cf. Ponte 2008). Entre os Tupinambá de Olivença cada indivíduo pode ser identificado por dois ou três nomes diferentes, entre apelidos e o nome do registo de nascimento. O termo "apelido" é normalmente descritivo de nomes que associam a pessoa a características da sua personalidade, a aparências físicas ou mesmo a aspectos relacionais.

Os Tupinambá de Olivença integram sob uma mesma categoria de “apelidos" um conjunto diverso de tipos de nome, tais como "cognomes afectuosos, trocistas ou ocasionais", como acontece noutros contextos no Brasil, inclusive indígena ( $v d$. o caso dos Txicão, Menget 2001: 263). Entre os Tupinambá de Olivença, os “apelidos" englobam pelo menos três tipos de nomes: a) os nomes jocosos que descrevem de forma caricatural particularidades físicas ou morais das pessoas; b) os nomes afectivos, tipificados pelos diminutivos; c) os nomes fonéticos construídos a partir de sílabas que se conjugam na produção de sentido fonético.

O primeiro nome próprio que se dá a um bebé é quase invariavelmente um "apelido", dado pela mãe e outros parentes que circunstancialmente encontrem um nome divertido para a criança. Quando a criança cresce, este apelido é substituído por outro e/ou pelo nome de registo. Os apelidos das crianças são frequentemente trocistas, mas também afectivos e carinhosos. Assim, uma criança a quem se chama "cabeça" ou "careca" ou "cuia" provoca o riso de

3 Neste texto sigo os termos usados no Brasil: "apelido" para o que em Portugal chamamos "alcunha" e "sobrenome" para o que em Portugal chamamos "apelido". 
quem pronuncia o seu nome, mas é um riso que muitas vezes se confunde com uma certa forma de afecto, da qual até a mãe chega a ser cúmplice, como se a troça, neste caso, fosse sempre uma forma de suscitar compaixão e nunca de tocar o perigoso limiar que a pode levar à agressão provocatória.

Como observou Pina Cabral, o registo comunitário de interacção é definicional dos apelidos: "são nomes que não se escrevem (...), dados pela comunidade ao indivíduo (...) normalmente independentemente da sua escolha explícita" (Pina Cabral 1984: 150). No caso da sociabilidade na região da roça de Olivença verifiquei que a perpetuação de apelidos desta natureza depende principalmente da reputação de um indivíduo entre os seus consociados. Assim, por exemplo, um homem conhecido em Sapucaeira - localidade da região da mata/roça de Olivença onde sediei o trabalho de campo - pelo apelido de "Tainha" era frequentemente confrontado com situações onde a justificação do seu nome se reafirmava, enquanto os rumores sobre a sua pessoa ressoavam. Certa vez, à minha frente e de vários homens, num ambiente de afirmação de identidade masculina, fizeram-lhe perguntas sucessivas para que ele pronunciasse a palavra "farinha" - uma das palavras que mais se repete num meio onde se produz farinha de mandioca - já que em consequência de uma deficiência de fala ele trocava o "F" pelo " $\mathrm{T}$ " e por isso dizia "tainha". Cada vez que ele pronunciava "tainha" provocava o riso generalizado entre a assistência, confirmando assim pela interacção a justificação do seu apelido. Mas para além desse contexto, o apelido legitimava-se socialmente e o riso em torno de Tainha ecoava nos rumores sobre a sua pessoa.

Certa vez uma menina confessou-me suspeitar que este homem "vira lobisomem", partindo do testemunho de uma irmã já casada que lhe contara que certa noite ouvira umas unhas afiadas arranhar a porta de sua casa e concluira ter sido "o Tainha virado lobisomem". Relatou-me que ele teria entrado na cozinha, virado o caixote do lixo e assustado as galinhas e os gatos. No dia seguinte, Tainha apareceu arranhado e com restos de pêlos de cachorro na boca, o que comprovava a sua tese de ter sido ele a entrar na casa da irmã, virado lobisomem. Ela mesma, aliás, havia testemunhado uma ocorrência que confirmava ele "virar" lobisomem, quando sentiu um "bicho" a entrar em casa e a fazer grande alvoroço, tendo até comido um animal. No dia seguinte, foi o próprio Tainha quem perguntou ao pai dela se não o tinham visto lá em casa na noite anterior. Ainda a reforçar o argumento, dizia que numa outra localidade onde ele anteriormente morara e que não ficava muito longe dali se sabia que "ele virava", concluindo que a explicação final para tudo isto era que, segundo se dizia, ele era "marido da mãe" (praticava o incesto).

Um outro apelido trocista era aplicado a um rapaz relativamente jovem conhecido pelo nome "dendê" por ter o cabelo muito ruivo - cor-de-laranja como a cor do óleo de dendê. O contexto de interacção, performativo, que dava o sentido verdadeiramente jocoso ao apelido surgia quando o interpelavam 
com uma provocação: já posso começar a preparar a moqueca? ${ }^{4}$ Nunca vi transformar-se este contexto de jocosidade em agressão verbal, excepto quando o convívio já é à partida agonístico, como em situações de brigas em ónibus ou em festas onde a maioria dos presentes estão embriagados. Nestas situações, os apelidos jocosos podem tornar-se estigmatizadores, colocando a pessoa numa situação limiar entre o riso e o sarcasmo.

Um outro tipo de apelidos que conheci em Sapucaeira como nomes jocosos, mas também fortemente afectivos, são aqueles que têm por referência categorias étnico-raciais. Assim, por exemplo, um jovem com uma fisionomia índia particularmente marcante tinha o apelido de "caboclo". Num meio social onde todos os índios usavam a expressão caboclo para se referirem a si próprios, o apelido "caboclo" atraía sobre si um lastro de ambivalências. Assisti a diversos episódios em que chamavam este rapaz "caboclo", imprimindo na expressão vocal do chamamento um certo tom jocoso e fazendo comentários sobre as suas supostas capacidades mais "selvagens" - por exemplo, maior agilidade para subir a um pé de coqueiro, menor capacidade de conversação, etc.

Os nomes com referência étnico-racial podem, no entanto, assumir um papel mais afectuoso do que jocoso, como no caso de uma mulher igualmente índia que era conhecida pelo apelido de Nega. Ainda que o tom da sua pele seja mais escuro do que o de outros índios, Nega estava longe de ter aparência de "negra" na Bahia, pois nesta região predomina uma população mestiça afro-brasileira. Assim, o seu apelido não suscitava comentários a partir do que o nome conota, como acontecia com o caboclo, acabando por ser usado também como um nome afectivo, um diminutivo do seu nome de registo: Neuza.

Os nomes afectivos derivam de corruptelas ou diminutivos do nome de registo, nomes que são também epítetos que podem derivar de certa particularidade física ou moral, mas não são trocistas e sim modos intimistas de chamamento. Assim, por exemplo, uma mulher de estatura muito baixa era chamada Miúda e, tal como no caso de Nega, este apelido era sempre invocado de um modo afectuoso, pois Miúda (cujo nome de registo é Maria da Hora) era uma mulher de idade e muito respeitada em Sapucaeira, conhecida pela sua atitude normalmente tímida. Os nomes afectuosos podem também ser diminutivos, como Chico para Francisco, Miguelzinho para Miguel, Diulcinha para Diulce, ou ainda Juju para Delice ou Deda para Pedrísia.

Um último tipo de apelidos, os nomes fonéticos, constrói-se a partir de uma lógica estritamente lexical, parecendo apenas orientar-se por regras mínimas de fonética, criando combinações originais ou nomes singulares a partir de sílabas curtas (como acontece com os nomes de registo de que tratarei na secção seguinte). Repare-se nos exemplos que se seguem deste tipo de apelidos e suas relações com os nomes de registo, relativos aos filhos de dois casais da mesma geração. 
Quadro 1

Exemplos de nomes fonéticos.

$\begin{array}{ll}\text { Nome de Registo } & \text { Apelido } \\ \text { Daiane } & \text { Nóca } \\ \text { Darlene } & \text { Pota } \\ \text { Darlete } & - \\ \text { Joeliane } & \text { Tongo } \\ \text { Joseane } & \text { Dego } \\ \text { Jilson } & \text { Bilu } \\ \text { Joceli } & \text { Preta } \\ \text { Celma } & \text { Cibira } \\ \text { Islami } & \text { Moquinha } \\ \end{array}$

Esta combinação de tipos de apelidos é muito recorrente no registo de interacção quotidiana entre os Tupinambá de Olivença, mas o seu poder de identificação da pessoa não é considerado superior ao dos nomes do registo de nascimento. Mais ainda, como este último caso dos nomes fonéticos nos mostra, a lógica de construção dos apelidos pode aproximar-se muito da que é utilizada na criação de nomes para o registo de nascimento. Veremos, contudo, que enquanto que os apelidos criam nomes singulares referenciados pela comunidade, os nomes do registo de nascimento estabelecem formas de se relacionar mais selectivas.

Os apelidos e nomes de registo dos Tupinambá de Olivença não constituem e nem constituíram no passado repertórios a transmitir ao longo do tempo: cada nome individua, seja a partir de referentes comunitários seja a partir de formas múltiplas e historicamente variáveis de criar relação, como as que vamos encontrar nos nomes do registo de nascimento.

\section{NOMES DO REGISTO DE NASCIMENTO: O "NOME CERTO”.}

Em 1997, ao solicitar informação sobre os nomes das pessoas para os diagramas genealógicos, verifiquei que os meus interlocutores se espicaçavam mutuamente para me dar "o nome certo" e não "o apelido". O "nome certo" corresponde ao nome próprio e sobrenome tal como consta no registo de nascimento - em certos contextos diziam também "a assinatura".

Seria difícil não reconhecer hoje a importância dos nomes do registo de nascimento para os Tupinambá de Olivença. Para dar início ao processo de reivindicação de direitos indígenas face ao Estado brasileiro foi preciso fazer chegar à Fundação Nacional do Índio vários documentos com “as assinaturas" de um número significativo de pessoas reivindicando a sua identificação como "povo indígena" - estatuto que desde os finais do século XIX lhes tinha sido retirado (cf. Viegas 2007: 23-27). Desde o reconhecimento como "povo indígena” que o valioso acesso à assistência de saúde diferenciada, por exemplo, depende do nome de cada um estar registado no censo realizado em 2004 pelo organismo de saúde indígena federal (FUNASA). Ao longo do processo de luta política e de identificação da terra indígena, os Tupinambá de Olivença vão assinando constantemente actas de reuniões que confirmam a sua presença e a anuência às decisões tomadas face ao organismo federal indígena (FUNAI). 


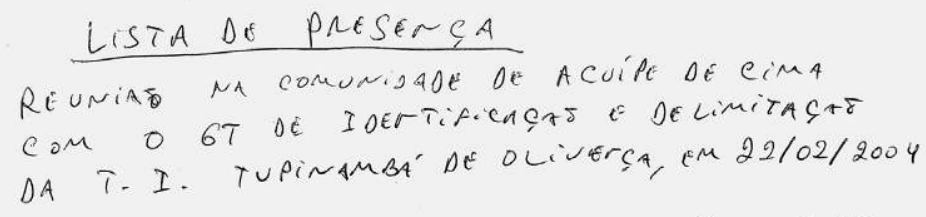

- Nome Arigelica bumbo de ferso

1. Golisul eunka de zesus Sapucacisapucaura

2. Mario zosi Siltra Naximento compo são pedero

3- Ediearlos Souza Vierra.

1 - Mari a, Valdelice Amaral de yeran. Acaupe do cneio

S- Forsenuce Sauza Sranco, eacique. OLivENCA

- difir da naazio bunha , Acuipe do Mluo

- Frontíses Arasiza de fjesus Serpucareira 1

8- Juomilda oliveira sontona Sapucarevio 1

9- Rosevnldo Acuipla do meío 2

10. Joed mallo SE SESUS CARUALLA nCUIPE DE BAIXO

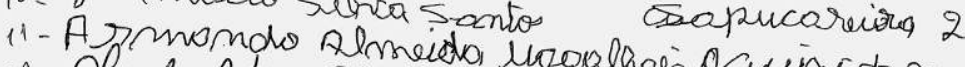

12. Afaudis Antonid At Magolhado- Qhivenca - seale maivo

"4- Surzanga Finsira da Silva

15. Selilares maria Silva

16. On anias siha santors

17- Prispiriano do siba 18 tors sapucacira 2

19- Sle Santos Pachesranegra

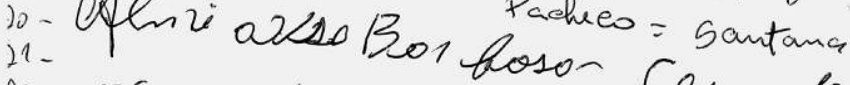

22. OSmario de obideico Cera do Badeiso

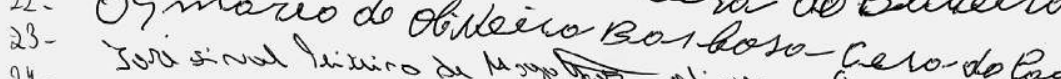

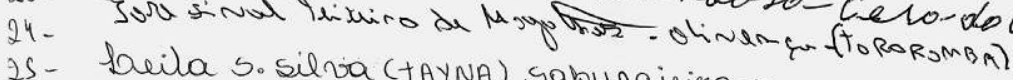

25- beila S. silva (

26 - Selma sihra santos sapue alina II

28. Pedrr B pelio levera sopucaieira I.

29. Maristeler sautios dibing $\rightarrow$ Cxiper do Miv I I

30- caramido de Sousa Ferrevia

31 - gelzon vacimenta da Silvia

33 - you ziva Barbaro

$34-$

$35-$

Figura 1

Excerto da lista de presenças numa reunião no âmbito do processo de identificação da terra indígena Tupinambá de Olivença (2004). 
A valorização dos nomes do registo de nascimento não terá surgido apenas como resultado desta experiência mais recente de acesso a direitos indígenas. Desde o final da década de 1980 (quando se deu a abertura democrática no Brasil) o acesso a certos direitos sociais (tais como a aposentadoria) veio atribuir um valor exacerbado aos registos civis para os Tupinambá de Olivença. No final da década de 1980, um dos responsáveis pelo cartório da vila de Olivença, que também era de família de índios, foi fazer o registo de nascimentos de muitos índios que viviam na roça, alertando para a importância deste acto para o direito de acesso a aposentadorias e também para a identificação dos índios da região. Ouvi vários relatos sobre este facto, muitas vezes efabulando as peripécias passadas no percurso deste homem que, durante um mês, registou a população da região rural para o interior de Olivença, particularmente a indígena. As pessoas mais idosas também mencionavam este episódio com frequência, explicando que a data do seu nascimento é realmente incerta, porque foi calculada apenas nessa altura quando elas já eram adultas.

A crescente valorização dos registos civis tem um tal poder simbólico entre os Tupinambá de Olivença que cheguei a ouvir casais afirmarem que o seu casamento não é oficial porque só contraíram matrimónio "no padre". Certa vez uma mulher de meia-idade explicava o que queria dizer com esta ideia:

Casados no padre é a mesma coisa que ser solteiro. O povo diz que na lei é amasiado. O povo aqui diz que o padre é amasiado. O povo diz que o casamento é civil.

Para uma população indígena missionada no século XVII pelos jesuítas e em tantos outros aspectos seguidora de visões do mundo influenciadas pelo catolicismo, o facto ganha particular relevância e contribui para compreender esta sobrevalorização atribuída, até ao nível discursivo, aos registos civis (dos quais fazem parte os registos de nascimento).

Entre os nomes do registo de nascimento mais comuns na actualidade comecemos por sublinhar a predominância de um certo tipo de nomes individuados que encontramos de modo muito difundido no Brasil contemporâneo, principalmente os nomes seriados. Estes nomes foram definidos por João de Pina Cabral, a partir do estudo em Valença (Baixo Sul baiano) como casos em que "vários filhos têm nomes iniciados com a letra ou a sílaba inicial do nome do pai; quando se dá a um filho um nome que conjuga sílabas de ambos os pais (...) ou quando os nomes de dois filhos são iguais excepto pela sílaba inicial" (cf. Pina Cabral 2007: 69). Os nomes de duas irmãs - "Dai-ane" e "Dar-lete" -, assim como Cris-ti-ane e Cris-ti-ele que são filhas de Cris-ti-na são exemplos, assim como os apresentados na Figura 2. 
Figura 2

Exemplos de nomes seriados entre os Tupinambá de Olivença

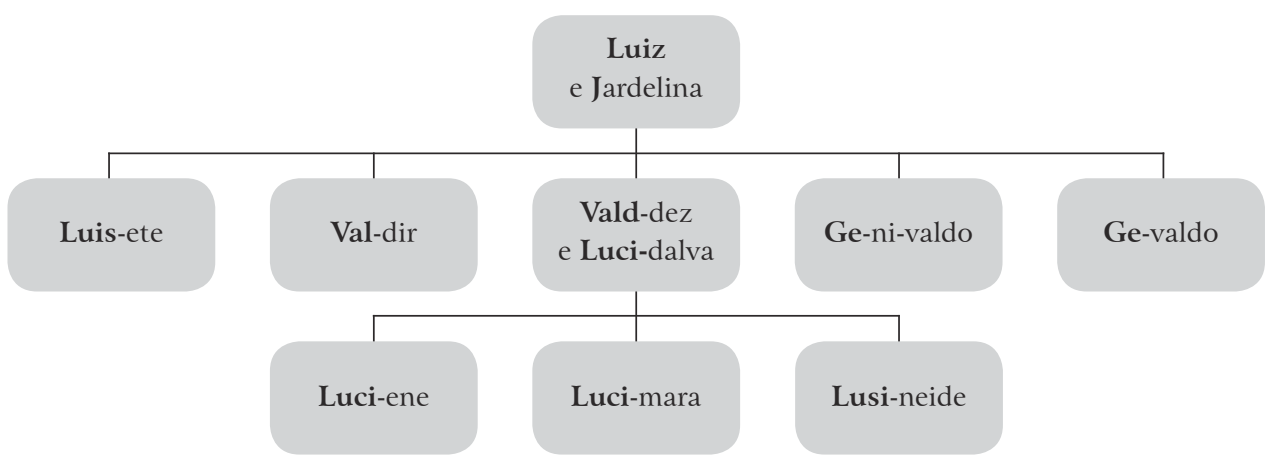

No caso dos Tupinambá de Olivença é muito comum que as séries se façam apenas entre irmãos e não entre pais e filhos, como por exemplo Luisete e Gustavo, que deram como nomes aos filhos: Elielson, Elizenil, Elizeu. Estas serialidades não se constroem propriamente a partir da transmissão de nomes familiares anteriores e nem dela resulta a edificação de uma "unidade de parentesco". As poucas observações justificativas que ouvi aos Tupinambá de Olivença a respeito dos nomes seriados sublinham o facto de estes nomes constituírem uma espécie de mnemónica inspirada na relação entre pais e filhos (mesmo quando apenas estabelecem relações entre irmãos). Assim, ouvi contradizer a ideia de que exista uma tendência actual para se pôr "nomes difíceis" aos filhos pela afirmação de que lembrá-los fica facilitado por serem "uma combinação a partir do nome do pai (ou da mãe)". O resultado deste tipo de combinações é uma maior diferenciação dos nomes, quando comparados com os nomes tradicionais portugueses que os Tupinambá de Olivença usavam no passado, como analisarei na próxima secção. Os nomes pessoais do registo de nascimento que os pais dão aos seus filhos desde a década de 1980 (com incidência grande já desde 1960) são, assim, nomes singulares: seriados e relacionais (porque ligam parentes) ou estrangeirados.

Para além do nome próprio, o nome do registo de nascimento também incorpora os sobrenomes. Contudo, e diferentemente dos nomes próprios que ganham tanto valor e são usados em muitos casos na interacção quotidiana, os sobrenomes não são usados para identificar tão fortemente as inserções familiares dos Tupinambá de Olivença. O assunto merece particular atenção. Como tenho vindo a descrever com maior desenvolvimento noutros textos, actualmente os Tupinambá habitam idealmente em "unidades compósitas de 
residência" (Viegas 2007: 73-80, 112-1 17). Poderíamos dizer que o conjunto de pessoas que habita uma unidade compósita de residência constitui normalmente uma "família extensa", mas os processos de independência das casas e as dinâmicas de parentesco mostram-nos que o conceito não descreve por completo o modelo de relações de parentesco que ocorre nesse tipo de vivência habitacional. O lugar é de qualquer forma o referente principal na construção da pessoa entre os Tupinambá de Olivença, na maneira como ela se torna um ser-no-mundo e como se constitui o processo referencial de parentesco (cf. Viegas 2003; 2007: 112-117).

O nome de referência para designar estes "lugares" é o nome pessoal de uma das pessoas que o fundou: "o lugar de Miguel", por exemplo. Quando se quer designar as pessoas desse "lugar" diz-se, por exemplo, "o pessoal de Luiz", "os de Luiz" ou "o pessoal de Miguelina”, "o lugar de Miguelina”. Este nome de referência familiar contrasta com o que é descrito para outros contextos de roça no Brasil e para contextos indígenas com uma história de relação com os processos de civilização e colonialismo próxima da dos Tupinambá de Olivença, mas inseridos na diferente tradição Jê. No seu trabalho etnográfico sobre a roça na região das matas de Minas Gerais, Comerford explica que, pelo contrário, aí se usam sobrenomes como referentes para as "famílias": "os Camargo", "os Teles" e "os Oliveira” (cf. 2003: 47). Esta mesma significação dos sobrenomes tem sido igualmente observada para o caso dos Pataxó (Jê) que habitam na Bahia, como também pude constatar no conhecimento que tive das suas relações familiares nos contactos estabelecidos com os índios de Olivença em 1997-1998.

No período de trabalho de terreno de 1997-1998, acompanhei situações que mostravam que os Tupinambá de Olivença não consideravam que os sobrenomes pudessem efectivamente servir de referente nem para a identificação de famílias, nem de relações entre famílias. Os índios Pataxó e Pataxó Hã Hã Hãe, que residem em áreas indígenas relativamente próximas de Olivença (a cerca de $100 \mathrm{~km}$ num caso e 300 noutro), por diversas vezes procuraram "parentes" seus em Olivença perguntando aos Tupinambá sobre "os Braz" e "os Moniz" - que são considerados por eles "sobrenomes de índios Pataxó" que eles julgavam poderem incluir índios provenientes de Olivença. Enquanto que esta referência ao sobrenome fazia sentido para os Pataxó como uma forma de pesquisar o passado das relações territoriais e familiares entre índios no sul da Bahia, para os Tupinambá de Olivença, não só a procura de sobrenomes idênticos não parecia imediatamente um modo óbvio de legitimar a sua "indianidade”, como eles não viam nesta procura de linhas genealógicas pelos Pataxó um meio significativo de estabelecer relações entre os dois povos indígenas.

A um primeiro nível, temos que explicar esta subvalorização dos sobrenomes na identificação de grupos familiares entre os Tupinambá de Olivença como o típico efeito homogeneizador do processo de colonização, já que, no 
conjunto da população recenseada em 2004 existem 43\% que são Santos e $25 \%$ que são Silva. O facto tem sido largamente sublinhado e é muito claro também para outros casos no sul da Bahia (cf. Pina Cabral 2007).

Mas a um segundo nível, os Tupinambá de Olivença e particularmente os de Sapucaeira poderiam, caso o quisessem, ter meios para encontrar uma forma de correlação entre certos sobrenomes, a inserção familiar e a identificação étnica: em Sapucaeira há alguns sobrenomes que efectivamente só pertencem a famílias de índios, tais como os Cunha e Damásio (veja-se também Paula 2001). O que estou aqui a sugerir, em suma, é que o uso do sobrenome como um meio de inscrever relações familiares entre os Tupinambá de Olivença é utilizado quando se refere "a assinatura", mas não é valorizado enquanto tal.

Em suma, ao mesmo tempo que o uso de nomes vinca a sua condição de subalternidade (aproximando-os, por exemplo, da população de Valença) essa condição é também resultado da forma específica como os nomes foram mediando a história do poder em Olivença: a relação entre os Tupinambá de Olivença e o Estado. Os nomes seriados criam mais uma relação familiar (entre irmãos e/ou entre pais e filhos) perante o Estado: um tipo de inscrição que está menos dependente do tipo de inserção familiar geracional e genealógica veiculada pelos sobrenomes e utilizada, por exemplo, pelos seus vizinhos de raiz Jê (os Pataxó). Não está em causa, claro está, uma apropriação tupi dos generalizados nomes seriados, mas uma sobreposição de níveis de relação histórica entre estes ameríndios, o Estado e o meio social subalternizado onde se inscrevem, mas também onde desenvolvem estratégias de apropriação e de resistência à subalternidade.

O caso dos Tupinambá de Olivença mostra-nos, assim, que se "o nome de pessoa lusófono" se divide em duas partes, sendo o nome próprio distintivo da individualidade e o sobrenome da "inserção familiar" (Pina Cabral, neste volume), também verificamos que, para que o sobrenome ganhe sentido como distintivo familiar, ele tem que actuar de dois modos interdependentes: a) distinguir-se no contexto da comunidade; b) ganhar de modo mais ou menos intenso um significado de identificação familiar e de transmissão genealógica. Poderemos dizer, em suma, que o facto de os Tupinambá de Olivença terem dinâmicas de parentesco fortemente marcadas por uma subvalorização das relações traçadas genealogicamente também se reflecte nesta anulação do valor de identificação familiar do sobrenome (cf. Viegas 2007: 126-138). Mas o facto explica-se igualmente pela sua complexa relação com o Estado como "índios missionados", "índios civilizados", "caboclos" e agora "povo indígena". $\mathrm{O}$ processo histórico clarifica-se mais ainda quando analisamos as alterações nos nomes de registo de nascimento ao longo do último século. 


\section{UM SÉCULO DE MUDANÇAS NOS NOMES DO REGISTO DE NASCIMENTO:}

A análise do tipo de nomes pessoais dos registos civis dos Tupinambá de Olivença ao longo do último século será aqui sustentada em três tipos de materiais: primeiro, a análise inédita do arquivo do Cartório de Olivença (1889-1910); segundo, o arquivo da Fundação Nacional de Saúde (2004); terceiro, os levantamentos genealógicos (1997-1998 e 2003-2004). Estas fontes permitem chegar ao mapeamento dos nomes de registo usados pelos Tupinambá de Olivença desde o primeiro ano em que se fizeram registos civis de nascimentos e óbitos no Brasil - 1889 (cf. Fausto 1994: 251) - até à actualidade..$^{5} \mathrm{O}$ material aqui analisado diz respeito ao registo de nomes para os índios residentes em todo o território entre 1889 e 1910 , enquanto que, para o período seguinte, me sustento apenas nos dados relativos à localidade de Sapucaeira. Este recorte justifica-se por Sapucaeira ser a localidade que tem maior número de índios nesta região de Olivença (cf. Viegas 2007: 36-37) e sobre a qual tenho maior conhecimento etnográfico.

A análise do tipo de nomes usado pelos Tupinambá de Olivença neste último século mostra-nos a existência de uma mudança ocorrida entre 1960 e 1980, correspondente a duas transformações fundamentais do sistema onomástico praticado pelos Tupinambá de Olivença: a primeira diz respeito à repetição de nomes no passado por contraste com a sua não repetição no presente, em que predomina o nome singular, original. Se nos cingirmos aos registos de nascimento entre 1889 e 1902, verificamos que 60\% dos nomes próprios dos homens e 30 \% dos nomes próprios das mulheres se repetiam e que o uso de um repertório repetido de nomes se prolonga até à década de 1960. Num contraste quase absoluto, os nomes dos Tupinambá de Olivença residentes em Sapucaeira e nascidos nos últimos vinte anos (entre 1984 e 2004) praticamente não se repetem. Entre as 200 crianças e adolescentes nascidos neste período há apenas 5 que têm nomes repetidos (dois Alex e três José), representando apenas 2,5\% de casos de repetição: 97,5\% dos nomes não se repetem. Assim, em termos percentuais o número de repetições é ainda mais baixo do que no caso da base de dados das escolas de Valença estudado por João de Pina Cabral, onde se verificam cerca de 30\% de repetições em adolescentes nascidos neste mesmo período para 70\% de nomes não repetidos (Pina Cabral 2007: 84).

Um segundo contraste entre o tipo de nomes dos registos no passado e aquele que encontramos a partir das décadas de 1940-1960 é marcado pelo uso quase exclusivo, no passado, de nomes portugueses tradicionais; o que contrasta com a enorme percentagem de nomes seriados a partir da década de 1960.

5 Para ultrapassar lapsos nos livros de registo de nascimento uso aqui como fontes os registos de nascimento entre 1889 e 1902 e os registos de óbito entre 1889 e 1910. Uso o material de arquivo para comparar com o que recolhi em levantamentos genealógicos em 1997-1998 e em 2003-2004 entre a população indígena de uma das localidades da região de Olivença - Sapucaeira. 
Nos nomes registados neste últimos vinte anos há apenas alguns nomes portugueses tradicionais, como José ou Domingos, e pela primeira vez aparecem nomes estrangeirados, como Welson ou Elton, como ilustra o quadro 2.

Quadro 2

Excerto da lista dos nomes do registo de nascimento e de óbito em Olivença (entre 1889 e 1910) e em Sapucaeira (entre 1920 e 2004) em intervalos de cerca de 20 anos. $^{6}$

\begin{tabular}{|c|c|c|c|c|}
\hline 1889-1902 & 1915-1943 & 1944-1963 & 1964-1983 & 1984-2004 \\
\hline Maria & Irene & Marilene & Gevaldo & Andresa \\
\hline Manuel & Domingas & Clarice & Genivaldo & Elaine \\
\hline Domingos & Jardelina & Gildarte & Edna & Joildo \\
\hline António & José & Valdelice & Eliane & Jozimar \\
\hline Maria & José & Iraci & Pedrísia & Jonisson \\
\hline Lourenço & Maria & Moacyr & Eliana & Emerson \\
\hline Manuel & José & Ineide & Ana Lúcia & Ronaldo \\
\hline Ângela & Manoel & Almir & Jilson & Eric \\
\hline João & Edite & Luzia & Joselina & Elaine \\
\hline Manuel & José & Samuel & Manoel & Joedson \\
\hline Maria & Vicente & Denival & Nilzete & José \\
\hline Eusébia & Milton & Maria José & José & Weleson \\
\hline Juviniano & Benício & Osvaldo & José & Elton \\
\hline Josepha & Maria & Abinael & Angélica & Gabriel \\
\hline Maria & Orlando & Maria & Cristina & Cristiane \\
\hline Elutério & Paulino & José & José Carlos & Cristiele \\
\hline Manuel & Clarice & Enock & Marceliano & Magno \\
\hline Maria & Maria Delci & Maria & Manoel & Magnobaldo \\
\hline Bárbara & Sebastião & Jeová & Noemildes & Jaciane \\
\hline Júlia & Rosalvo & Conceição & Luciene & César \\
\hline Pedro & Balbino & Dilce & Valdir & Douglas \\
\hline Pedro & Manoel & Conceição & Edinice & Valdeir \\
\hline João & Dejanira & Agnobaldo & Gilson & Thiago \\
\hline Miguel & Augusto & Neuza & Luisete & Jaires \\
\hline Francisco & Nivalda & Gustavo & Elielson & Clebson \\
\hline Deolinda & Altina & Miguelina & Elizenil & Domingos \\
\hline Ismael & Augusto & Tereza & Elizeu & Loilson \\
\hline Pedro & Osvaldo & Balbino & Adenilta & Eronildo \\
\hline João & & Delice & Alfredo & Ivanildo \\
\hline Manuel & & Maria & Joelita & Alda \\
\hline
\end{tabular}

6 Total de indivíduos entre 1920-2004: 192; Registos de Nascimento e Óbito do Cartório de Olivença (1889-1910): 394. 


\begin{tabular}{|c|c|c|c|c|}
\hline $1889-1902$ & $1915-1943$ & $1944-1963$ & 1964-1983 & $1984-2004$ \\
\hline Maria & & Roque & Marcelo & Ueldes \\
\hline Maria & & Manoel & Valdeci & Leitícia \\
\hline João & & Valdeci & Valdez & Maricélia \\
\hline
\end{tabular}

No censo da população realizado em 2004, o registo de nomes dos Tupinambá de Olivença nascidos entre 1920 e 1940 são ainda predominantemente nomes tradicionais portugueses, como se verifica no quadro 3, onde apresento a lista completa de nomes dos Tupinambá de Olivença residentes em Sapucaeira em 2004 e nascidos nesse período:

Quadro 3

Lista completa dos nomes dos Tupinambá de Olivença nascidos entre 1920 e 1940 e residentes em Sapucaeira em 2004.

$\begin{array}{lll}\text { Edna } & \text { Edite } & \text { Sebastião } \\ \text { Irene } & \text { José } & \text { Rosalvo } \\ \text { Domingas } & \text { Vicente } & \text { Balbino } \\ \text { Jardelina } & \text { Milton } & \text { Arlinda } \\ \text { José } & \text { Benício } & \text { Manoel } \\ \text { José } & \text { Maria } & \text { Dejanira } \\ \text { Maria } & \text { Orlando } & \text { Augusto } \\ \text { José } & \text { Paulino } & \text { Nivalda } \\ \text { Manoel } & \text { Clarice } & \text { Altina } \\ \text { Maria Delci } & \text { Ortência } & \text { Augusto }\end{array}$

A análise das genealogias que recolhi em campo e que abrangem entre três e quatro gerações (recuando até ao início do século XX) mostra-nos que, mesmo no período em que os Tupinambá de Olivença usaram o repertório de nomes tradicionais portugueses (um repertório muito restrito e, portanto, repetido), não se verifica a transmissão de nomes próprios entre gerações. O processo de mudança do sistema onomástico dos Tupinambá de Olivença verificado entre as décadas de 1960 e 1980 deve ser pensado principalmente a partir de uma reflexão abrangente das vivências socioeconómicas ocorridas neste mesmo período na região e no Brasil, pois prende-se com fenómenos como a proletarização rural na região de Olivença, aspirações (por vezes estritamente idealizadas) à sociedade de consumo e, ao mesmo tempo, com as transformações da relação com Estado, no que respeita ao acesso a direitos sociais. Todos 
estes factores se conjugam na específica história da construção deste território ao mesmo tempo ameríndio, fundiário, colonial e missionário.

As décadas de 1940-1960 e depois de 1970-1980 correspondem em primeiro lugar à concretização de uma mudança decisiva na vida territorial dos Tupinambá de Olivença. Como já demonstrei noutros textos, o sistema fundiário começou a implantar-se nesta região na década de 1930, mas foi apenas na década de 1970 que os Tupinambá de Olivença ficaram na situação de efectiva restrição do seu modo de relação com o território, ao tornar-se inviável a manutenção de um sentido ilimitado do espaço que era imprescindível à abertura cíclica de novas áreas de residência na mata (cf. Viegas 2007: 212-225, 265-270; Viegas no prelo-a). Entre a década de 1980 e a actualidade chegou-se à situação agora verificada de que, se usarmos os parâmetros de classificação das fazendas na região, a maioria dos lugares dos Tupinambá não chega a ter $1 \%$ do tamanho considerado para as pequenas propriedades fundiárias em Sapucaeira (cf. Viegas 2007: 77). Mais ainda, esses espaços estão actualmente intercalados por áreas de propriedade privada de fazendeiros.

A esta alteração da situação fundiária correspondeu alguma proletarização dos índios como trabalhadores assalariados no fabrico da farinha de mandioca. Nos finais da década de 1970, o fim do boom do cacau em Ilhéus trouxe para a região de Olivença muitos trabalhadores não-índios. Estes, vindos do interior da Bahia ou do estado do Sergipe, após o fim do boom não encontraram mais emprego nas fazendas de cacau. Nas décadas de 1970 e 1980 dá-se efectivamente uma profunda transformação demográfica em toda a região de Ilhéus, bem patente nos números do Instituto Brasileiro de Estatística (IBGE): nos sessenta anos anteriores (entre 1920 e 1980), a população de Ilhéus aumentou de 13.000 para 131.000; em apenas uma década (entre 1980 e 1991) aumentou para o dobro (223.482); enquanto que entre 1991 e 2005 até diminuiu ligeiramente para 221.110 (IBGE, Andrade 1996: 22).

Desde a década de 1980, os Tupinambá de Olivença convivem diariamente com os seus vizinhos não-índios. Nunca transformaram os espaços de habitação confinados em guetos de convivialidade étnica. Mantiveram, porém, um modo de pertença ao espaço marcado por dinâmicas de parentesco e de género próprias, que diferem da restante população pela intimidade máxima na relação entre os que são da mesma área de habitação ou "lugar", valorizando "laços de proximidade imediata" e intensificando a experiência pessoal directa (Viegas 2007: 285-287).

O espaço da roça de Olivença é hoje marcado também pela historicidade ameríndia, onde a autonomia de pequenas áreas de residência e vizinhança não é necessariamente sobreposta por sociabilidades comunitárias, chegando a haver algum anonimato. É comum, por exemplo, que pessoas que vivem em áreas relativamente próximas se conheçam pela primeira vez num ponto de ónibus ou num "bodego" (venda) - locais privilegiados para a sociabilidade 
em círculos mais vastos que ultrapassam as visitas entre casas e o convívio em vendas (cf. Viegas 2007: 188-190). A sociabilidade alargada não está marcada, portanto, por princípios comunitários, como acontece, por exemplo, na região da roça da mata de Minas Gerais estudada por Comerford, onde se reproduzem éticas comunitárias: os moradores possuem "mapas das relações de parentesco em uma região relativamente extensa" e estão sujeitos a uma "rede de observação mútua" e reforçada pela actualização da narrativa comunitária, segundo a qual "aqui é todo mundo parente" (cf. Comerford 2003: 32-34).

Na roça de Olivença, os espaços de sociabilidade fortemente marcados pela sociedade de consumo e sobrevalorização da identidade pessoal que, por exemplo, João de Pina Cabral identificou para Valença como fenómenos correlacionados com a valorização discursiva dos nomes "diferentes" (cf. Pina Cabral 2007: 82), não são tão predominantes no convívio quotidiano. Na região rural de Olivença, por exemplo, não há electricidade e, portanto, o acesso às novelas e à mediatização é comparativamente menor. Mas a observação sobre a relação entre estes nomes "diferentes" e "difíceis" e essa valorização da imagem pessoal é também uma realidade particularmente acentuada entre as adolescentes femininas, que desde mais cedo circulam entre a roça e a cidade (cf. Viegas 2007: 159-164). Os bodegos, os campos de futebol em dia de jogo e as viagens de ónibus (que ligam as várias localidades desta região de roça à cidade de Ilhéus) são contextos privilegiados para a circulação de bens de consumo e para a troca de experiências relacionadas com um estilo de vida associado simbolicamente à cidade. As mulheres Tupinambá de Olivença têm maior experiência nesta alternância entre a roça e a cidade por razões socioestruturais e históricas (cf. Viegas 2007: 159-164; no prelo-b). Em Sapucaeira é nos bodegos que mais circulam objectos, imagens e conversas ligadas com valores de consumo indicativos da valorização da identidade pessoal através, por exemplo, da valorização do corpo feminino. Como as casas em Sapucaeira não têm electricidade, é também comum que seja nos bodegos, onde normalmente há gerador, que se juntem adolescentes a ver novelas. Nelas se inspiraram certamente os pais que deram aos filhos nomes estrangeirados. ${ }^{7}$

Podemos dizer, em suma, que os adultos Tupinambá de Olivença que, na década entre 1980 e 1990, começaram a dar nomes seriados que individuam os seus filhos, têm estado certamente a experienciar de forma articulada essa mudança do sistema onomástico e um conjunto de outras mudanças sociais. Por um lado, os nomes adquiridos nas novelas começaram a surgir, mas em menor número do que o verificado, por exemplo, em Valença, enquanto que os nomes seriados, obtidos por conjugações fonéticas são mais frequentes. Estes nomes estabelecem relações exactamente entre o círculo mais restrito de consociados. 
Ao mesmo tempo são nomes singulares que garantem a individuação, mesmo neste novo círculo abrangente e anónimo de sociabilidade. Tanto neste sistema contemporâneo como no passado, os nomes para os Tupinambá de Olivença (mesmo quando nomes tradicionais portugueses) não constituem um registo fixo usado para a transmissão e continuidade geracional. Nesse sentido, eles estão tanto agora como há um século atrás radicalmente longe da atribuição ao sobrenome de um sentido patrimonial, como nos casos portugueses mais tradicionais (Pina Cabral, neste volume; Lima 2007).

\section{CONCLUSÃO}

Neste texto salientei a importância dos nomes do registo de nascimento entre os Tupinambá de Olivença e a sua alteração ao longo de um século. Há um século atrás, os Tupinambá de Olivença tinham um repertório de nomes restrito, enquanto que das décadas de 1960-1980 até à actualidade passaram a dar nomes próprios aos filhos que são criados a partir de elos ínfimos (letras, sílabas) dos nomes dos pais e/ou irmãos, claramente procurando que sejam singulares e menos repetidos do que na situação do passado.

Mostrei que entre os Tupinambá de Olivença ter um nome que crie individuação é ter, por um lado, um nome não-tradicional e, por outro, na medida em que ele seja seriado, também é ter um nome necessariamente mais parecido com o de um outro parente do que com o de um outro alguém cuja identificação se desconhece em absoluto. A composição do nome faz-se a partir de partículas/elementos do nome de alguém próximo (pais ou irmãos), ao mesmo tempo que não se faz, por exemplo, de partes do nome dos avós, apelando para formas de criar relações no presente, mais do que para continuidades com relações no passado. Não posso deixar de integrar esta observação nos processos de constituição do parentesco que tenho vindo a descrever etnograficamente (cf. Viegas 2003). Os aspectos performativos e essencialmente revogáveis do parentesco, tão marcantes da socialidade dos Tupinambá de Olivença, fazem aqui sentido na compreensão dos aspectos da onomástica usada por eles. Mais ainda, o nome seriado relacional consolida as relações entre aqueles que são consociados. Estes nomes relacionam e, como dizem os Tupinambá, também são "difíceis" (por contraste com os nomes tradicionais portugueses) mas são garantidamente originais num espaço de sociabilidade agora muito mais vasto.

Na roça de Olivença a autonomia da socialidade entre os Tupinambá e a flutuação relativa da população assalariada rural acentuam, por um lado, a "desunião" (como alguns dizem) ou o não-comunitarismo alargado e, por outro, uma construção da pessoa marcada pela intimidade do lugar onde todos têm também nomes singulares, mas que, ao mesmo tempo, reforçam certas relações familiares. Na medida em que estas relações se estabelecem no nome do registo de nascimento (a "assinatura" com a qual acedem a direitos sociais), 
temos que ver o processo também como uma espécie de reforço da pessoa familiar como cidadão.

O estudo dos nomes evidencia, portanto, uma multiplicidade de formas de individuação e a maneira como estas se combinam com diferentes referenciais éticos - de inserção comunitária (pelos apelidos) e de formas de constituir família face ao Estado, através do sistema dos nomes seriados. Estas dimensões articulam-se, ainda, com a questão do tempo da socialidade: das formas de se subvalorizar a transmissão de nomes, cargos e bens entre gerações (como acontece, pelo contrário, entre os Pataxó, tendo sido também eles sujeitos a uma história longa de colonização, mas no seu caso de origem Jê). Vimos, ainda, que estes nomes singulares e relacionais constroem um certo tipo de individuação que valoriza a identidade pessoal e se inscreve nas práticas de nominação hegemónicas na região do Baixo Sul da Bahia e de muitos outros meios sociais brasileiros na actualidade (onde predominam os nomes seriados e estrangeirados).

Por fim, a análise desenvolvida neste texto mostra que, em casos como os Tupinambá de Olivença, que durante um século não foram reconhecidos pelo Estado como índios, este acesso aos direitos indígenas é mediado pelos registos civis, sobrevalorizando o nome do registo de nascimento. Por isso, hoje, para os Tupinambá de Olivença, o poder do nome na sua identidade oficial é tão patente. Através do nome, ou "assinatura", realizam negociações de grande relevância para o reconhecimento de direitos sociais, num caminho que reconstitui a pessoa face ao Estado, criando uma nova categoria, que a legislação brasileira ainda não reconhece, mas que os movimentos indígenas vão tornando cada vez mais evidente: a cidadania indígena.

\section{BIBLIOGRAFIA}

ALMEIDA, Rita Heloísa, 1997, O Diretório dos Índios: Um Projeto de "Civilização" no Brasil do Século XVIII. Brasília, Editora UnB.

ALMEIDA, Heloísa Buarque de, 2007, "De vida distantes e de afetos familiares: os nomes da mídia”, em João de Pina-Cabral e Susana de Matos Viegas (orgs.), Nomes: Género, Etnicidade e Família. Coimbra, Almedina, pp. 245-264.

ANDRADE, Maria Palma, 1996, Ilhéus: Passado e Presente. Salvador, BDA.

BODENHORN, Barbara, e Gabriele Vom Bruck, 2006, "Entangled in histories: an intro-

duction to the anthropology of names and naming", em Bodenhorn e Vom Bruck, The

Anthropology of Names and Naming. Cambridge, Cambridge University Press, pp. 1-30.

CARSTEN, Janet, 2004, After Kinship. Cambridge, Cambridge University Press. 
COMERForD, John Cunha, 2003, Como Uma Família: Sociabilidade, Territórios de Parentesco e Sindicalismo Rural. Rio de Janeiro, Relume Dumará.

GEERTZ, Clifford, 1993 [1973], "Person, time, and conduct in Bali”, em The Interpretation of Cultures. Londres, Fontana Press, pp. 360-41 1.

FAUSTO, Boris, 1994, História do Brasil. São Paulo, EdUSP.

FAUSTO, Carlos, 2001, Inimigos Fiéis: História, Guerra e Xamanismo na Amazônia. São Paulo, Editora da USP.

HARrison, Simon, 1990, Stealing People's Names: History and Politics in a Sepik River Cosmology. Cambridge e Nova Iorque, Cambridge University Press.

HUGH-JONES, Christine, 1988 [1977], From the Milk River: Spatial and Temporal Processes. Cambridge, Cambridge University Press.

HUGH-JONES, Stephen, 2006, “The substance of Northweast Amazonian names”, em Bodenhorn e Vom Bruck, The Anthropology of Names and Naming. Cambridge, Cambridge University Press, pp. 73-96.

HUMPHREY, Caroline, 2006, "On being named and not named: Authority, persons, and their names in Mongolia”, em Bodenhorn e Vom Bruck, The Anthropology of Names and Naming. Cambridge, Cambridge University Press, pp. 157-176.

LIMA, Antónia Pedroso de, "Intencionalidade, afecto e distinção: as escolhas de nomes em famílias de elite de Lisboa”, em João de Pina-Cabral e Susana de Matos Viegas (orgs.). Nomes: Género, Etnicidade e Família. Coimbra, Almedina, pp. 39-61.

MAUSS, Marcel, 1985 [1938], "A category of the human mind: the notion of person; the notion of self, em M. Carrithers, S. Collins e Steven Lukes (eds.), The Category of Person: Anthropology, Philosophy, History. Cambridge, Cambridge University Press, pp. 1-25.

MAYBURY-LEWIS, David, 1975 [1967], Akwe-Shavante Society. Nova Iorque e Londres, Oxford University Press.

MENGET, Patrick, 2001, Em Nome dos Outros. Lisboa, Assírio e Alvim.

MOTT, Luís, 1988, "Os índios do sul da Bahia: população, economia e sociedade (1740-1854)”, Cultura: Os Índios na Bahia, n. ${ }^{\circ}$ 1, pp. 93-116.

PAULA, Jorge Luiz de, 2001, Relatório FUNAI. Brasília, FUNAI.

PINA CABRAL, João de, 2007, “Mães, pais e nomes no baixo sul (Bahia, Brasil)”, em João de Pina Cabral e Susana de Matos Viegas (orgs.), Nomes: Género, Etnicidade e Família. Coimbra, Almedina, pp. 63-88.

—, 2002. Between China and Europe: person, culture and emotion in Macao. Londres e Nova Iorque, Continuum Press.

_ 1984, "Nicknames and the experience of community", Man, n.s. 19 (1): pp. 148-150.

PINA CABRAL, João de, e Susana de Matos Viegas, 2007, "Nomes e ética: uma introdução ao debate”, em João de Pina Cabral e Susana de Matos Viegas (orgs.), Nomes: Género, Etnicidade e Família. Coimbra, Almedina, pp. 13-38.

PONTE, Inês, 2008, Relatório Etnográfico: Nomes em Pessoas: Dar e Receber Nome em Una, Bahia, Brasil. Relatório da bolseira do projecto POCTI/ANT/61198/2004, Fundação para a Ciência e a Tecnologia, Instituto de Ciências Sociais (não publicado).

SCHRITZMEYER, Ana Lúcia Pastore, 2007, "Nomes em julgamento: práticas judiciárias padronizando identidades sexuais”, em João de Pina Cabral e Susana de Matos Viegas (orgs.), Nomes: Género, Etnicidade e Família. Coimbra, Almedina, pp. 79-120.

SEGALEN, Martine, 1980, "Le nom caché: la dénomination dans le pays bigouden sud", L'Homme, XX (4): pp. 63-76. 
SILVA, Aracy Lopes da, 1986, Nomes e Amigos: Da Prática Xavante a uma Reflexão sobre os Jê. São Paulo, FFLCH, USP.

VIEGAS, Susana de Matos (no prelo-a). “Compatibilidades Equívocas: A permuta de terra entre brancos e índios Tupi na costa sul da Bahia", em Carlos Fausto e John Monteiro (eds.), Tempos Índios: Narrativas do Novo Mundo. Lisboa, Assírio e Alvim.

—, (no prelo-b), "Mulheres transitivas: hegemonias de género em processos de mudança entre os Tupinambá de Olivença (Brasil)”, em Manuel Villaverde Cabral, Karin Wall, Sofia Aboim e Filipe Carreira da Silva (orgs.), Itinerários. A Investigação nos 25 Anos do ICS. Lisboa, Imprensa das Ciências Sociais.

__, 2007, Terra Calada: os Tupinambá na Mata Atlântica do Sul da Bahia. Rio de Janeiro e Coimbra, 7Letras/Almedina.

— 2003 , "Eating with your favourite mother: time and sociality in a South Amerindian community (South of Bahia/Brazil)", Journal of the Royal Anthropological Institute (including Man), 9 (1), pp. 21-37.

Viveiros De CASTRO, Eduardo, 1986, Araweté: Os Deuses Canibais. Rio de Janeiro, Jorge Zahar Editores.

WATSON, Rubie S., 1986, “The named and the nameless: gender and person in Chinese Society", American Ethnologist, 13, pp. 619-631.

Person and individuation: the power of names among the Tupinamba of Olivença (south of Bahia, Brazil) - Susana de Matos Viegas - Instituto de Ciências Sociais da Universidade de Lisboa • susana.viegas@ics.ul.pt

Departing from an analysis of social changes and the use of different name systems in civil records among the Tupinamba of Olivença (south of Bahia), this article develops a debate on the notion of the person, names and individuation. The relevance of "serial names" in Brazil and its use by the Tupinamba of Olivença point to different ways of constituting the person. The Tupinamba of Olivença appropriate these names both as a way of constituting family in the face of the State and of constructing themselves as persons in the rural environment of the roça in which they live their everyday life.

KEYWORDS: Person, names, Tupi, citizenship, kinship, amerindian history. 